\title{
Toughness-Strength Relations in the Overaged 7449 Al-Based Alloy
}

\begin{abstract}
N. KAMP, I. SINCLAIR, and M.J. STARINK
This article examines the relationship between plane strain fracture toughness, $K_{I c}$, the tensile properties, and the microstructure of the overaged 7449 aluminum-plate alloy, and compares them to the 7150 alloy. The 7449 alloy has a higher content of $\eta^{\prime} / \eta$ precipitates; and, the 7150 alloy contains a greater amount of coarse intermetallic particles, as it contains an appreciable amount of coarse $\mathrm{S}$ phase $\left(\mathrm{Al}_{2} \mathrm{CuMg}\right)$, which is largely absent in the 7449 alloy. The toughness of the alloys shows an increase on overaging, and the 7449 alloy shows a reasonably linear toughness - yield strength relation on extended overaging. Several mechanisms of failure occur: coarse voiding at intermetallics and a combined intergranular/transgranular shear fracture mode, with the former becoming more important as overaging progresses. Drawbacks of existing models for toughness are discussed, and a new model for plane strain fracture toughness, based on the microstructurally dependent work-hardening factor, $K_{A}$, introduced in Ashby's theory of work hardening, is developed. This model predicts a linear relation between $K_{I c}$ and $K_{A}^{0.85} / \sigma_{y s}^{0.35}$, where $\sigma_{y s}$ is the yield strength, which is consistent with the experimental data.
\end{abstract}

\section{INTRODUCTION}

COST reduction is a key objective of modern airframe manufacture. This can be achieved by the design of materials with improved properties leading to weight reduction of the airframe structure and, therefore, reduction in fuel consumption. The high-strength 7449 aluminum alloy was particularly developed to be used for the upper wing skin of aircraft structures replacing the established 7150 aluminum alloy. ${ }^{[1]}$ This relatively new alloy possesses a higher $\mathrm{Zn}$ content and slightly less $\mathrm{Cu}$ than the 7150 aluminum alloy. However, in aerospace design, damage tolerant concepts and, therefore, fracture toughness is a critical parameter. As high strength is known to be detrimental for toughness (e.g., Reference 2 ), it is relevant to analyze the influence of the strength and the microstructural conditions related to this high strength on the toughness of the alloy. The complex microstructure and multiple failure mechanisms of $7 \mathrm{xxx}$ (Al-Zn-Mg-Cu) alloys have undoubtedly hampered attempts to build a comprehensive model of plane strain fracture toughness $\left(K_{I c}\right)$ for these materials. Such modeling of toughness has been the subject of numerous studies, ${ }^{[3-6]}$ which show that a range of microstructural features can influence $K_{I c}$ : the coarse intermetallics (typically Fe or Si containing phases), ${ }^{[3]}$ the dispersoids (Zr-rich particles), ${ }^{[6]}$ the aging precipitates, ${ }^{[4,5,6]}$ and the grain structure.

To reveal the main relationships between fracture mechanisms and microstructure an extensive study of the microstructure together with mechanical tests is conducted in this study. The data are compared with current fracture toughness models, with the results being used to improve the modeling of toughness using microstructural parameters and basic tensile properties.

N. KAMP, Research Fellow, I. SINCLAIR, Lecturer, and M.J. STARINK, Reader, are with the Materials Research Group, School of Engineering Sciences, University of Southampton, Southampton SO17 1BJ, United Kingdom. Contact e-mail: m.j.starink@ soton.ac.uk

Manuscript submitted February 19, 2001.

\section{EXPERIMENTAL PROCEDURE}

The 7449 and 7150 plates, respectively 30- and 36-mm thick, were provided by Pechiney CRV (Voreppe, France) in a solutionized, quenched, and stretched condition (corresponding to the commercial W51 heat treatment). The nominal composition of the two alloys is given in Table I. Specimens were naturally aged for several months before undergoing three commercial heat treatments, which are presented in Table II. Here, it should be noted that one single T651 treatment was applied to both alloys. This treatment is designed to give peak strength for the 7449 alloy. Five experimental overaged heat treatments, T7A to T7E, have also been applied to the 7449 aluminum alloy (Table II).

Tensile tests on the materials were carried out, according to ASTM standard E-8. Specimens were taken in the longitudinal (L) orientation (i.e., parallel to the rolling direction).

Toughness tests were performed on compact tension specimens in accordance with the ASTM standard E-399. Specimens were taken in L-transverse (T) orientation. Tests were carried out on an INSTRON* 8801 servohydraulic machine.

*INSTRON is a trademark of Instron Co., Canton, MA.

For differential scanning calorimetry (DSC), slices of 0.5$\mathrm{mm}$ thickness were cut and punched to obtain 5-mm diameter discs. The samples were studied in a Shimadzu DSC-50, (Tokyo, Japan) and the reference employed was a pure aluminum disc of the same weight as the sample ( $\pm 5 \mathrm{mg}$ ). Further details on DSC experiments are given elsewhere. ${ }^{[7]}$

Optical microscopy and image analysis were used to characterize grain structures and intermetallic content. Intermetallic content was measured on as-polished samples, while grain structures were studied on polished and subsequently etched surfaces. Etching consisted of immersion in $10 \mathrm{pct}$ $\mathrm{H}_{3} \mathrm{PO}_{4}$ and 90 pct water at $50{ }^{\circ} \mathrm{C}$. Scanning electron microscopy (SEM) with energy dispersive X-ray spectrometry (EDS) was performed on polished sections of the 7150 and 7449 alloys to identify the coarse intermetallics.

Thin foils for transmission electron microscopy (TEM) 
Table I. Composition Ranges of 7449 and 7150 Alloys (Weight Percent)

\begin{tabular}{ccccccc}
\hline & $\mathrm{Zn}$ & $\mathrm{Mg}$ & $\mathrm{Cu}$ & $\mathrm{Zr}$ & $\mathrm{Fe}$ & $\mathrm{Si}$ \\
\hline 7449 & 7.5 to 8.7 & 1.8 to 2.7 & 1.4 to 2.1 & $<0.25$ & $<0.15$ & $<0.12$ \\
7150 & 5.7 to 6.7 & 1.8 to 2.7 & 1.5 to 2.3 & $<0.25$ & $<0.15$ & $<0.12$ \\
\hline
\end{tabular}

Table II. Heat Treatments Applied to the 7449 Aluminum Alloy

\begin{tabular}{cl}
\hline $\begin{array}{c}\text { Heat Treatment } \\
\text { Denomination }\end{array}$ & \multicolumn{1}{c}{ Description } \\
\hline T651 & $\begin{array}{c}\text { proprietary peak-aged treatment } \\
\text { proprietary aging treatment, slightly } \\
\text { overaged } \\
\text { T7951 }\end{array}$ \\
proprietary aging treatment, more \\
overaged \\
T7651 & W51 $+24 \mathrm{~h}$ at $120{ }^{\circ} \mathrm{C}+12 \mathrm{~h}$ at $165^{\circ} \mathrm{C}$ \\
T7A & W51 $+24 \mathrm{~h}$ at $120{ }^{\circ} \mathrm{C}+24 \mathrm{~h}$ at $165^{\circ} \mathrm{C}$ \\
T7B & W51 $+24 \mathrm{~h}$ at $120{ }^{\circ} \mathrm{C}+39 \mathrm{~h}$ at $165^{\circ} \mathrm{C}$ \\
T7C & W51 $+24 \mathrm{~h}$ at $170{ }^{\circ} \mathrm{C}$ \\
T7D & W51 $+48 \mathrm{~h}$ at $160{ }^{\circ} \mathrm{C}$ \\
T7E &
\end{tabular}

were prepared using a standard procedure: samples of 300$\mu \mathrm{m}$ thickness were cut, ground to $150 \mu \mathrm{m}$, and electropolished using a 1/3 nitric acid and 2/3 methanol solution at $-20{ }^{\circ} \mathrm{C}$ to $-30{ }^{\circ} \mathrm{C}$, with a voltage of 12 . The TEM observation was performed at $200 \mathrm{kV}$ using a JEOL* JEM-

*JEOL is a trademark of Japan Electron Optics Ltd., Tokyo.

2000FX. The 7150 T7951, 7150 T7651, 7449 T7951, 7449

T7651, and 7449 T7E samples were studied.

An SEM investigation of the fracture surfaces has also been carried out. Fracture behavior in the plane strain zone (specimen center line) has been particularly studied. Edgeon observation of fracture surfaces together with polished and etched sections, revealing underlying microstructures, have been performed by SEM. Polished and etched sections of arrested crack specimens were also examined by optical microscopy for both alloys in T651, T7951, and T7651 conditions.

\section{MODELING OF TOUGHNESS}

\section{A. Existing Approaches}

Several models to analyze toughness on the basis of microstructural parameters have been published in the literature (e.g., Hahn and Rosenfield ${ }^{[3]}$ and Garrett and Knott ${ }^{[4]}$ ). These models typically employ simplifying approximations of near-crack-tip stresses and critical conditions at the crack tip. Garrett and Knott, ${ }^{[4]}$ as well as other researchers before them, ${ }^{[5]}$ have argued that the critical condition at the crack tip is reached when the strain exceeds a critical value, $\varepsilon_{c}^{*}$, over a critical distance. Using experimental studies by Hahn and Rosenfield ${ }^{[5]}$ which showed a linear relation between the length of the plastic zone ahead of the crack tip and $n^{2}$, where $n$ is the work-hardening exponent, they expressed their model as

$$
K_{I c}=C_{n} \sqrt{\sigma_{y s} \varepsilon_{c}^{*}}
$$

where $K_{I c}$ is the fracture toughness, $C$ is a constant, and $\sigma_{y s}$ is the yield strength. The latter relation between $K_{I c}, n$, and $\sigma_{y s}$ is common to the works of Garrett and Knott, and Hahn and Rosenfield. We will refer to this equation and the derivation in Reference 3 as the Garrett and Knott model; the models mentioned previously are applied and further analyzed in recent literature. ${ }^{[6,8,9]}$

This model gives a relation between the fracture toughness and the tensile properties of the alloy without providing any direct relationship to the microstructure. The work-hardening coefficient, $n$, is an experimentally derived term and is not explicitly related to the microstructure. Generally, $n$ depends on the yield strength, $\sigma_{y s}$, and the correlation of these tensile properties masks their individual influence on the toughness of the alloy. These limitations of the model reduce its value with regards to property optimization studies of the heat treatable Al-based alloys, in which strength can be readily varied through variation in heat treatment and variation of composition, and strength-toughness balance is often one of the key criteria. Hence, a different approach to modeling, aimed at deriving quantitative expressions for the decrease in toughness with increasing strength, incorporating clear microstructural influence on work hardening may be beneficial.

\section{B. New Approach}

Macroscopic flow behavior may be expressed in terms of yield strength and strain hardening. While the first is reasonably well-defined, strain hardening is less straightforward. Strain-hardening mechanisms depend on microstructure and are generally divided into several regimes with different corresponding equations, depending on the strainhardening mechanism at play. ${ }^{[10]}$ Strain hardening is often quantified using a purely empirical, exponential equation, based on the Ramsberg-Osgood equation, which is expressed as

$$
\frac{\varepsilon}{\varepsilon_{0}}=\frac{\sigma}{\sigma_{0}}+\alpha\left(\frac{\sigma}{\sigma_{0}}\right)^{\beta}
$$

where $\varepsilon$ is the strain; $\sigma$ is the stress; and $\varepsilon_{0}, \sigma_{0}, \alpha$, and $\beta$ are constants. The plastic part can be approximated as

$$
\sigma=A \varepsilon_{p}^{n}
$$

where $A$ is a constant, $\varepsilon_{p}$ is the plastic strain, and $n$ is the work-hardening exponent.

In contradiction to Eq. [2] the Ashby ${ }^{[11,12]}$ theory of strain hardening due to nonshearable particles and grain boundaries leads to a square-root strain-hardening expression, which has been given as (also References 13 and 14).

$$
\begin{aligned}
\sigma & =\sigma_{y s}+M\left(0.35 G_{m} \sqrt{\frac{\mathbf{b}}{d_{g}}}+0.25 G_{m} \sqrt{\frac{\mathbf{b} f_{n s}}{2 r_{n s}}}\right) \sqrt{\varepsilon_{p}} \\
& =\sigma_{y s}+K_{A} \sqrt{\varepsilon_{p}}
\end{aligned}
$$

where $M$ is the Taylor factor, ${ }^{[15]} \mathbf{b}$ is the Burgers vector, $d_{g}$ is the grain size, $f_{n s}$ is the volume fraction of nonshearable particles, $r_{n s}$ is the radius of nonshearable particles, $K_{A}$ is the strain-hardening factor, and $G_{m}$ is the shear modulus. For nonshearable particle types of varying sizes and volume fraction, it holds that 
$K_{A}=M\left(0.35 G_{m} \sqrt{\frac{\mathbf{b}}{d_{g}}}+0.25 G_{m} \sqrt{\frac{\mathbf{b} f_{n s, 1}}{2 r_{n s, 1}}+\frac{\mathbf{b} f_{n s, 2}}{2 r_{n s, 2}}}\right)$

where $f_{n s, i}$ and $r_{n s, i}$ are, respectively, the volume fraction and radius of the different type of nonshearable particle.

For typical 7xxx alloys in underaged conditions, precipitates are generally shearable, and from microstructural data presented in the literature, ${ }^{[16]}$ it is estimated that $K_{A}$ is about 150 to $300 \mathrm{MPa}$, with grain size having the most important influence. For overaged (T7) samples, coarsened precipitates will become nonshearable and contribute to an increase in $K_{A}$. As Ashby noted ${ }^{[12]}$ the preceding equations are only valid over a limited strain range, roughly for $\varepsilon_{p}$ between about 0.01 to 0.05 . This means that $\sigma_{y s}$ in Ashby's rootstrain work-hardening regime may deviate to some extent from a conventional 0.2 pct proof stress.

The two work-hardening equations/models shown previously give different stress-strain curves; however, Eq. [2] can be used to approximate Eq. [3] and vice versa over specific ranges of $\varepsilon$. For the purpose of the present article, we analyzed the relations between $n$ and $K_{A}$ by fitting Eq. [2] to [3] for a range of $K_{A}$ and $\sigma_{y s}$ values typical for medium to high strength Al-based alloys, over the plastic strain range 0.01 to 0.05 . It was observed that for the optimized (fitted) $n$ values, in good approximation, it holds that

$$
n=C_{1}\left(\frac{K_{\mathrm{A}}}{\sigma_{y s}}\right)^{\gamma}
$$

where $\gamma$ and $C_{1}$ are constants. For static tensile properties typical of high strength aluminum alloys, $\gamma$ equals about 0.85 . This relation, which was derived on a purely mathematical basis, provides some physical insights. For instance, the predicted decrease in $n$ with increasing yield strength is generally observed experimentally.

The latter equation presents a quantitative interpretation of what has been described as the "reduction in capability for strain hardening with increasing strength" and particularly explains in a quantitative manner why $n$ reaches a minimum at peak strength. Note that the "reduction in capability for strain hardening with increasing strength" is very much dependent on the type of strain-hardening expression used: $n$ depends directly on strength, i.e., a change in strength will always cause a change in $n$, but $K_{A}$, as used within the Ashby model, is not directly dependent on strength, provided that the population of nonshearable objects and defects is constant. For example, if in a given alloy the volume fraction of shearable precipitates increases as a result of precipitation, strength will increase and as a direct result $n$ will decrease, while $K_{A}$ is expected to remain constant. If shearable particles grow to become nonshearable, strength will decrease and as a direct result $n$ will increase, while $K_{A}$ is expected change only slightly, as according to Eq. [4] $K_{A}$ is determined by the sum of a range of terms, of which growing precipitates is only one.

In terms of toughness modeling, it may be shown that if the relative contributions from different fracture mechanisms do not vary with strength, $\varepsilon_{c}^{*}$ can be considered to be a constant. From Eq. [5] combined with Garrett and Knott's expression for ductile fracture, ${ }^{[4]}$ the following expression for the toughness is derived:

$$
K_{I c}=\sqrt{\frac{2 C E \varepsilon_{c}^{*} \sigma_{y s} n^{2}}{1-v^{2}}}=C_{1} \sqrt{\frac{2 C E \varepsilon_{c}^{*}}{1-v^{2}}} K_{A}^{\gamma} \sigma_{y s}^{0.5-\gamma}
$$

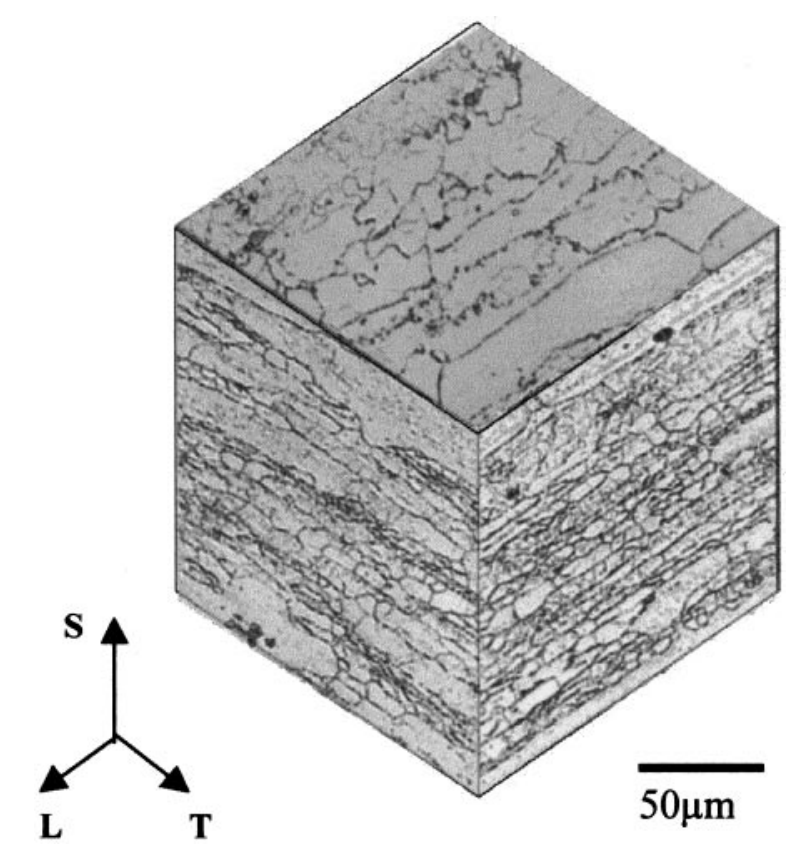

Fig. 1-Optical micrograph of the 7449 W51 alloy from polished and etched sections.

where $E$ is Young's modulus, $v$ is Poisson's ratio, and $C$ is a constant.

This equation shows that if $K_{A}$ and $\varepsilon_{c}^{*}$ are constant, i.e., if the distribution of nonshearable particles and the grain structure is constant, with only one fracture mechanism occurring, $K_{I c}$ reaches a minimum when $\sigma_{y s}$ reaches a maximum. This is the first time that this point, which has often been observed in experiments, is captured by an analytical model.

\section{RESULTS}

\section{A. Grain Structure}

Optical micrographs of the 7449-alloy grain structure are presented in Figure 1. The grain structure of the 7150 alloy is similar, and it is observed that the grain structure of both alloys is elongated in $\mathrm{T}$ and $\mathrm{L}$ directions and that coarse $(>1 \mu \mathrm{m})$ particles are present in the alloys. These particles are known to be intermetallic phases containing especially $\mathrm{Fe}, \mathrm{Si}$, and $\mathrm{Cu} .^{[16,17]}$

Both alloys exhibit a certain amount of recrystallization. From the optical micrograph in Figure 1, the amount of recrystallization is estimated at 20 pct for the 7449 alloy and 30 pet for the 7150 alloy.

The grain size in the short transverse direction, $d_{S}$, has been measured by the mean linear-intercept method. For the 7150 alloy, $d_{S}$ is slightly larger (about $16 \mu \mathrm{m}$ ) than for the 7449 alloy, for which $d_{S}$ is about $12 \mu \mathrm{m}$ (Table III). For both alloys, a wide range of subgrain sizes was seen ( 3 to $10 \mu \mathrm{m})$.

\section{B. Intermetallics}

Optical microscopy showed that intermetallics are inhomogeneously distributed; they mainly appeared as bands of particles oriented in the rolling direction. Intermetallics were 
Table III. Microstructural Properties of 7150 and 7449

\begin{tabular}{lccccccr}
\hline & \multicolumn{2}{c}{ Intermetallic Phase (Vol Pct Fraction) } & & \multicolumn{3}{c}{ Grain Sizes $(\mu \mathrm{m})$} & \\
\cline { 2 - 3 } \cline { 5 - 6 } Alloy & $\mathrm{Mg}_{2} \mathrm{Si}$ & $\mathrm{Al}_{7} \mathrm{Cu}_{2} \mathrm{Fe}$ and $\mathrm{Al}_{2} \mathrm{CuMg}$ & & $d_{\mathrm{S}}$ & $d_{\mathrm{L}}$ & $d_{\mathrm{T}}$ & Fraction Recrystallized (Pct) \\
\hline 7150 & 0.15 & 1.5 & 0.75 & 16 & 79 & 34 & 30 \\
7449 & 0.17 & 12 & 60 & 20 & 20 \\
\hline
\end{tabular}

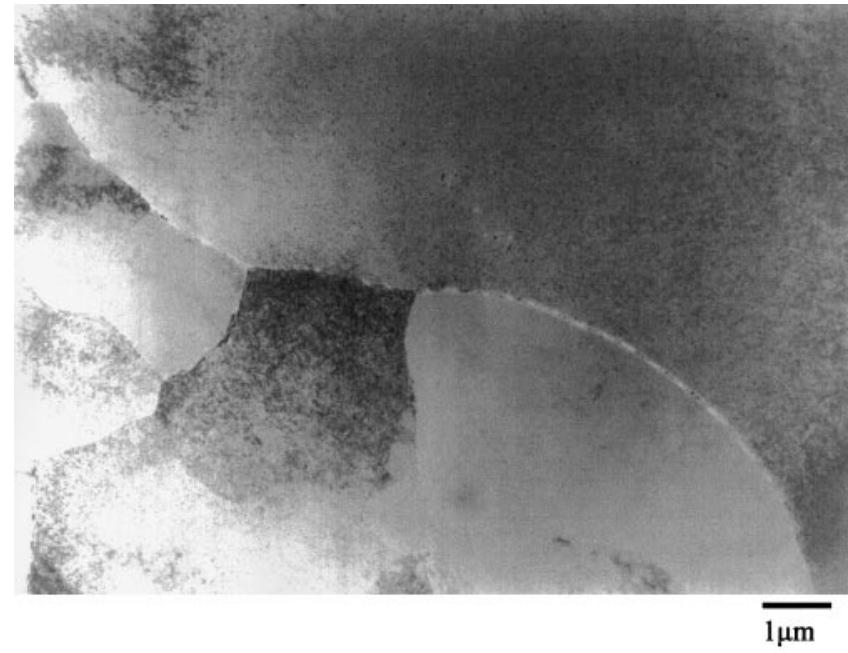

Fig. 2-TEM micrograph of the grain structure of the 7449 T7951 alloy, bright field.

especially observed in recrystallized grains. The coarse intermetallic particles were examined in SEM. This analysis exhibited two different kinds of $\mathrm{Cu}$ containing particles, one containing $\mathrm{Al}, \mathrm{Fe}$, and $\mathrm{Cu}$, which is believed to be $\mathrm{Al}_{7} \mathrm{Cu}_{2} \mathrm{Fe}$, and the other $\mathrm{Al}, \mathrm{Mg}$, and $\mathrm{Cu}$. In agreement with the literature, ${ }^{[17]}$ the latter were identified as $\mathrm{S}$ phase $\left(\mathrm{Al}_{2} \mathrm{CuMg}\right)$. The EDS analysis of some of the smaller particles, which appear black in the optical micrographs, showed that they contain $\mathrm{Si}$ and $\mathrm{Mg}$, and they are identified as $\mathrm{Mg}_{2} \mathrm{Si}$. The image analyzer enabled particles to be distinguished by their gray level, and their area fractions were determined. For both alloys, the area fraction of black particles $\left(\mathrm{Mg}_{2} \mathrm{Si}\right)$ is about 0.2 pct. Of the two alloys studied, the 7150 alloy contains the greater amount of gray particles $\left(\mathrm{S}\right.$ and $\mathrm{Al}_{7} \mathrm{Cu}_{2} \mathrm{Fe}$ ). Volume fractions of intermetallic phases are presented in Table III.

\section{TEM}

The TEM experiments reveal the grain structure, with Figure 2 showing both recrystallized grains and unrecrystallized regions. Details of the different precipitates are shown in Figure 3: a homogeneous distribution of small, i.e., $<50$ $\mathrm{nm}$, precipitates and somewhat larger dispersoids (presumably $\mathrm{Al}_{3} \mathrm{Zr}$ ) within the grain, with coarse $\eta$ particles at the grain boundary. The width of the precipitate free zone (PFZ) varies between 40 and $70 \mathrm{~nm}$ for the various treatments considered here; no distinct variation of PFZ width with degree of overaging was observed. Large variations in grainboundary precipitate size and area coverage of the grain boundaries within single samples were observed. Grain boundary precipitates are generally of ellipsoidal shape, elongated along the grain boundary. However, grain boundary precipitates having preferential orientations at an angle

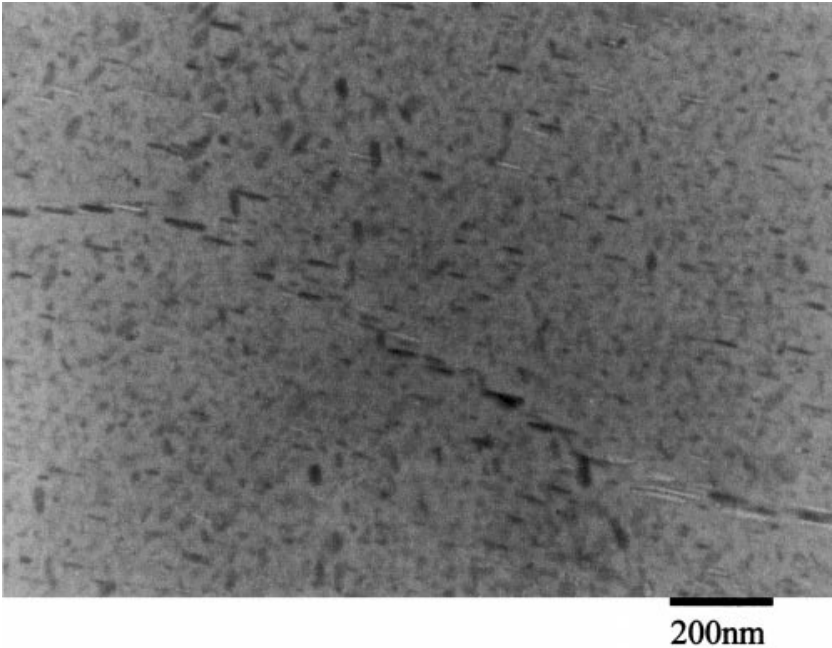

Fig. 3-TEM micrograph of grain boundaries and matrix precipitation of the 7449 T7B alloy, bright field.

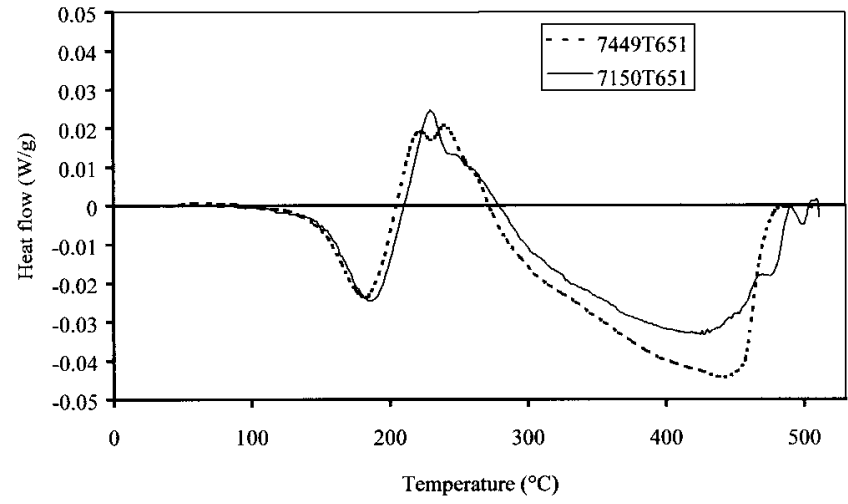

Fig. 4-DSC curves of the 7150 and 7449 alloys in T651 heat treatment conditions.

with the grain boundary have also been observed. Grainboundary precipitate sizes vary between 20 and $60 \mathrm{~nm}$ for the 7150 aluminum alloy, with no significant differences between T7951 and T7651, whereas for the 7449 aluminum alloy, precipitate sizes seem to vary from about $25 \mathrm{~nm}$ in the T7951 condition to $55 \mathrm{~nm}$ in the T7651 condition, with little further growth with further overaging to T7E.

\section{D. $D S C$}

Both alloys, in all the aging conditions applied, were studied by DSC, and results are presented in Figures 4, 5, and 6. All the DSC curves show similar general features (Figures 4, 5, and 6). The nature of the different peaks has been detailed in the literature. ${ }^{[18,19]}$ The peaks are numbered 


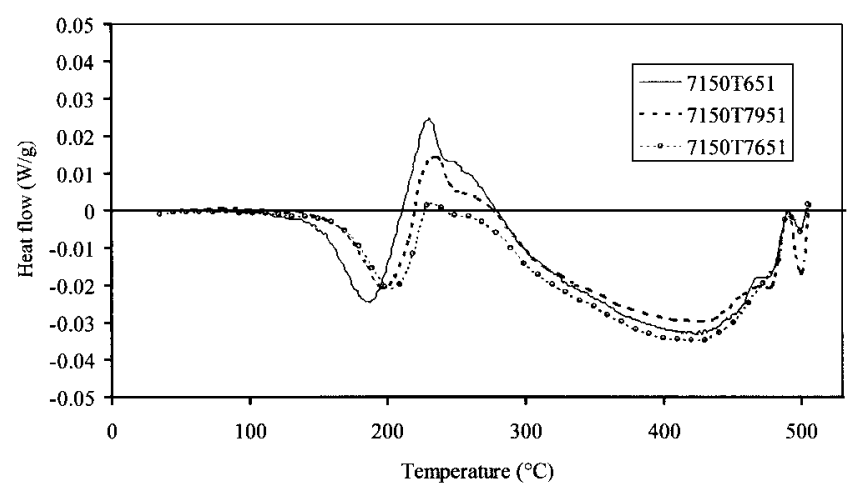

Fig. 5-DSC curves of the 7150 alloy for various heat treatment conditions.

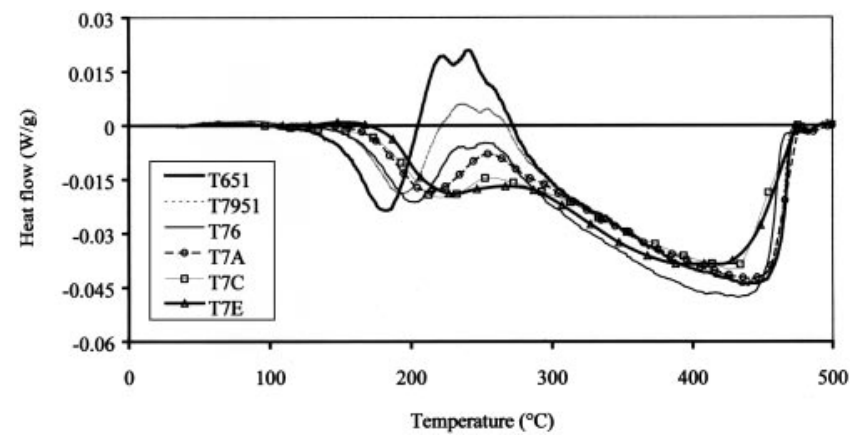

Fig. 6-DSC curves of the 7449 alloy for various heat treatments.

identical to earlier work, ${ }^{[18]}$ and their nature is discussed subsequently.

It should first be noted that in freshly quenched 7xxx alloys Guinier-Preston (GP) zone formation (an exothermic effect) is expected to occur at temperature lower than 150 ${ }^{\circ} \mathrm{C}$ during DSC scanning, but that in the present peak-aged and overaged alloys, no peak due to GP zone formation is observed. (This exothermic zone formation peak (peak I) has indeed been observed in the solution-treated and quenched 7449 alloy, where it occurs in the range of $30{ }^{\circ} \mathrm{C}$ to $100{ }^{\circ} \mathrm{C} .{ }^{[20]}$ ) These findings indicate that in the present alloy GP zone formation has been completed very early on in the aging treatments presently considered.

Several authors ${ }^{[18,19]}$ have shown that peak II (the first endothermic peak) represents mainly $\eta^{\prime}$ dissolution for peak-aged and overaged alloys, as this peak is similar for all overaged conditions where GP zones are already dissolved.

According to the literature, ${ }^{[19]}$ peak III is a combination of two main reactions, $\eta^{\prime}$ formation and growth, and $\eta$ formation. This gives a double peak shape in peak-aged and the slightly overaged condition, whereas in more overaged conditions, where $\eta^{\prime}$ has already grown to a large extent, only $\eta$ precipitation can been seen leading to a single peak shape. The total heat evolved decreases with increase in severity of the aging treatment, i.e., the amount of $\eta^{\prime}$ and $\eta$ forming during the DSC run, which depends on the remaining $\mathrm{Mg}$ and $\mathrm{Zn}$ dissolved in the Al-rich matrix to form the precipitates, is reduced with aging, thus reducing the total heat evolved. Similar trends were observed for 7xxx alloys that are leaner in $\mathrm{Zn} .^{[18]}$

The second endothermic peak (peak IV) corresponds to the dissolution of the phases present after precipitation (mostly stable $\eta$ ). This reaction is to a large extent determined by the equilibrium solvus of the dissolving phase(s) (e.g., the thermodynamic equilibrium between $\eta$ and the Alrich phase), ${ }^{[21]}$ and this equilibrium is temperature dependent. As the present T6 and T7 aging treatments will have little effect on the microstructure that the DSC samples have developed by the time the start of peak IV (about $280{ }^{\circ} \mathrm{C}$ ) is reached, this peak is very similar for all the samples.

For the 7150 alloy, an exothermic peak is found around $500{ }^{\circ} \mathrm{C}$ (peak VIII), which represents the melting of the $\mathrm{S}$ $\left(\mathrm{Al}_{2} \mathrm{CuMg}\right)$ phase. ${ }^{[18,22]}$ There is no evidence of any effect of aging on this peak, as it does not seem to vary systematically with the heat treatment. This indicates that this peak is sample dependent, involving $\mathrm{S}$ phase formed during ingot casting.

Throughout the various heat treatments, both alloys have a similarly shaped peak II, but the complex precipitation peak (peak III) shows marked changes. In the peak-aged condition the total heat that evolved during peak III is higher for the 7449 alloy (Figure 4). This can be explained by the higher $\mathrm{Zn}$ content of the 7449 alloy. However, in overaged conditions, the trend is reversed, and for T79 and T76 conditions, the 7150 alloy shows a higher exothermic heat evolution (Figures 5 and 6). This suggests that the rate of $\mathrm{Zn}$ precipitation during $\mathrm{T} 7$ treatments is higher for the 7449 alloy than for the 7150 alloy, causing the $\eta^{\prime}$ and $\eta$ precipitation peaks to decrease in size faster for the 7449 alloy. The higher amount of $\eta$ in the 7449 alloy is evidenced by the higher peak area of peak IV for all the aging treatments. The peak VIII, relating to $\mathrm{S}$ phase melting, does not appear at all in the 7449 alloy.

\section{E. Mechanical Tests}

The present materials are relatively high-strength aluminum alloys, with T6 yield strengths of $600 \mathrm{MPa}$ for the 7150 alloy and $625 \mathrm{MPa}$ for the 7449 alloy (Table IV). The yield strengths of 7449 are at least $20 \mathrm{MPa}$ higher than those of 7150 for all commercial heat treatments, which is in line with the literature. ${ }^{[1]}$ As expected, the yield strength decreases and the toughness increases on increasing overaging, i.e., in going from T651 to T7E for the 7449 alloy (Figure 7). In the T7951 and T7651 conditions, the two alloys show similar levels of toughness but with better strength properties in the 7449 alloy. It should be noted that the 7150 alloy in the T651 condition is not a fair comparison, as this T651 treatment corresponds to the 7449 and is not a standard peak-strength aging treatment for the 7150 alloy (it will in fact be slightly underaged). As overaging is increased from T651 to T7E for the 7449 alloy, the strength decreases in good approximation linearly with the increasing toughness.

For all tensile tests performed, the applicability of Ashby's work-hardening equation (Eq. [3]) was assessed and compared to the classical Ramsberg-Osgood equation (Eq. [2]) by fitting the corresponding equations to the experimental stress-strain curves (Figure 8). Root mean-squared error between the experimental data and the optimal modeled curves were calculated for both models and are reported in Table V. Thus, this table provides statistical information on the accuracy of these models. The fitting of the experimental stress-strain curves by the exponential model (Eq. [2]) and the Ashby model (Eq. [3]) revealed that for $0.01<\varepsilon_{p}<$ 0.05 the Ashby model is consistently more accurate than 
Table IV. Tensile and Fracture Toughness Tests Results

\begin{tabular}{|c|c|c|c|c|c|c|c|c|}
\hline Alloy & $\begin{array}{c}\text { Heat } \\
\text { Treatment }\end{array}$ & $\begin{array}{c}\sigma_{y s} \\
(\mathrm{MPa})\end{array}$ & $\begin{array}{c}\sigma_{\mathrm{UTS}} \\
(\mathrm{MPa})\end{array}$ & $\begin{array}{c}K_{I c} \\
(\mathrm{MPa} \sqrt{\mathrm{m}})\end{array}$ & $n$ & $K_{A}$ & $\begin{array}{l}\text { elongation } \\
\text { (Pct) }\end{array}$ & $\varepsilon_{c}^{*}$ \\
\hline \multirow[t]{3}{*}{7150} & T651 & 599 & 644 & 31.0 & 0.051 & 391 & 12.9 & 0.18 \\
\hline & T7951 & 572 & 617 & 29.2 & 0.055 & 396 & 11.4 & 0.20 \\
\hline & T7651 & 566 & 617 & 31.3 & 0.059 & 435 & 10.5 & 0.25 \\
\hline \multirow[t]{8}{*}{7449} & T651 & 627 & 665 & 25.6 & 0.041 & 365 & 12.6 & 0.27 \\
\hline & T7951 & 591 & 622 & 28.1 & 0.046 & 343 & 10.5 & 0.32 \\
\hline & T7651 & 584 & 614 & 31.3 & 0.047 & 392 & 11.1 & 0.37 \\
\hline & T7A & 512 & 561 & 34.3 & 0.063 & 455 & 12.6 & 0.43 \\
\hline & T7B & 472 & 535 & 39.4 & 0.082 & 549 & 13.2 & 0.49 \\
\hline & T7C & 421 & 498 & 43.7 & 0.103 & 622 & 13.6 & 0.64 \\
\hline & T7D & 426 & 500 & 42.7 & 0.104 & 569 & 14.5 & 0.66 \\
\hline & T7E & 404 & 481 & 45.4 & 0.108 & 560 & 15.0 & 0.69 \\
\hline
\end{tabular}

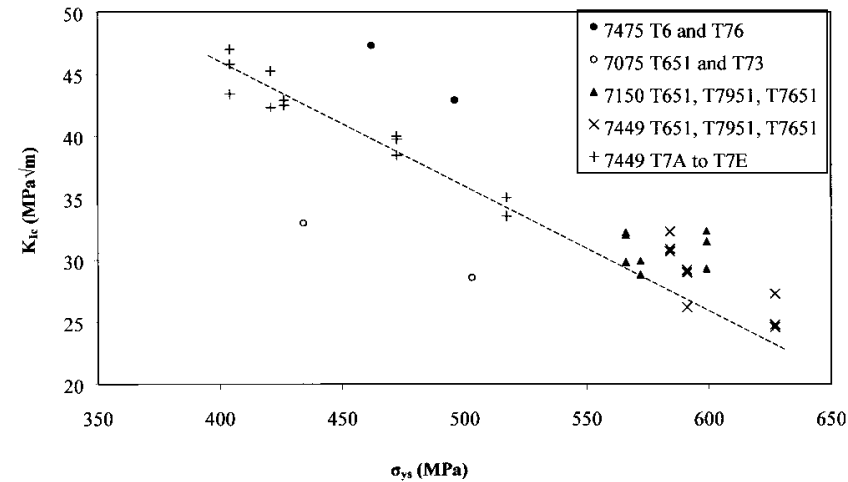

Fig. 7-Toughness vs yield strength of various Al-Zn-Mg-Cu alloys.

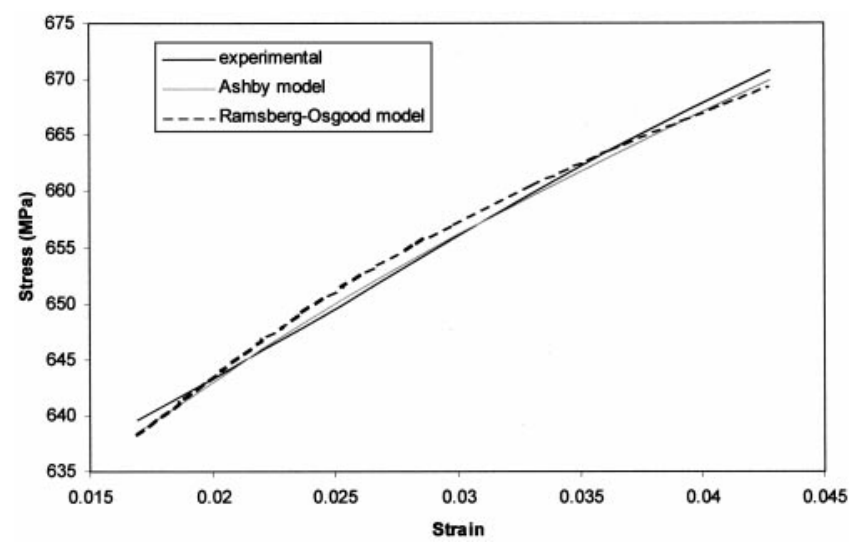

Fig. 8- Stress-strain curve of the 7150 T651 alloy and fitted curves of the Ashby and Ramsberg-Osgood models. the exponential fit. Over this range of strain, the average accuracy of the Ashby model is about $0.5 \mathrm{MPa}$, whereas the accuracy of the Ramsberg-Osgood model is on average about 1.1 MPa.

The strain-hardening parameters, $K_{A}$ and $n$, that are derived from the fits of the two models to the stress-strain curves show different trends with aging; $n$ increases consistently with aging for both alloys, whereas $K_{A}$ is initially approximately constant (in T6 and T79 conditions for both alloys) before a marked increase in the more overaged conditions (T76 for the 7150 alloy and T76 to T7E for the 7449 alloy).

The elongation to rupture of the two alloys is similar. The critical strain calculated from the reduction area in the tensile specimens showed a constant increase with overaging. This is associated with the more ductile rupture of the specimens, as will be discussed in the next section.

\section{F. Fractography}

From the fracture surfaces of the failed toughness samples, several features can be recognized (Figure 9). First, there is the presence of coarse voiding, with large intermetallics visible inside the voids (Figure 9(d)). The presence of ridges in the T direction (Figure 9(a)), which is the predominant grain boundary direction, suggests a competition between the intergranular and transgranular shear-fracture mechanisms. The ridges are linked to the grain boundary location (Figures 9(a), 10, and 11), but the grain structure suggests that the fracture following the linear features cannot be entirely intergranular, i.e., linkage of grain boundary failure in the $\mathrm{S}$ direction is partly transgranular. The features are similar for the two alloys. For both alloys, it is clear that the rupture

Table V. Yield Strength and Root Mean Square Error (RMSE) between Experimental Data and Ashby and Ramsberg-Osgood Models for the 7150 and 7449 Alloy in All Tested Heat Treatment Conditions; Reported Values are Averages over 3 Tensile Tests

\begin{tabular}{|c|c|c|c|c|c|c|c|c|c|}
\hline Alloy & & T6 & T79 & T76 & T7A & T7B & $\mathrm{T} 7 \mathrm{C}$ & T7D & T7E \\
\hline \multirow[t]{3}{*}{7150} & yield strength $(\mathrm{MPa})$ & 598 & 572 & 566 & - & - & - & - & - \\
\hline & RMSE (Ashby model) (MPa) & 0.62 & 0.51 & 0.73 & - & - & - & - & - \\
\hline & RMSE (Ramsberg-Osgood expression) (MPa) & 1.12 & 1.45 & 1.07 & - & - & - & - & - \\
\hline \multirow[t]{3}{*}{7449} & yield strength $(\mathrm{MPa})(\mathrm{MPa})$ & 632 & 591 & 578 & 518 & 472 & 420 & 426 & 405 \\
\hline & RMSE (Ashby model) (MPa) & 0.33 & 0.20 & 0.22 & 0.64 & 0.72 & 0.79 & 0.30 & 0.81 \\
\hline & RMSE (Ramsberg-Osgood expression) (MPa) & 0.67 & 0.13 & 0.28 & 1.68 & 1.92 & 1.20 & 0.31 & 1.51 \\
\hline
\end{tabular}



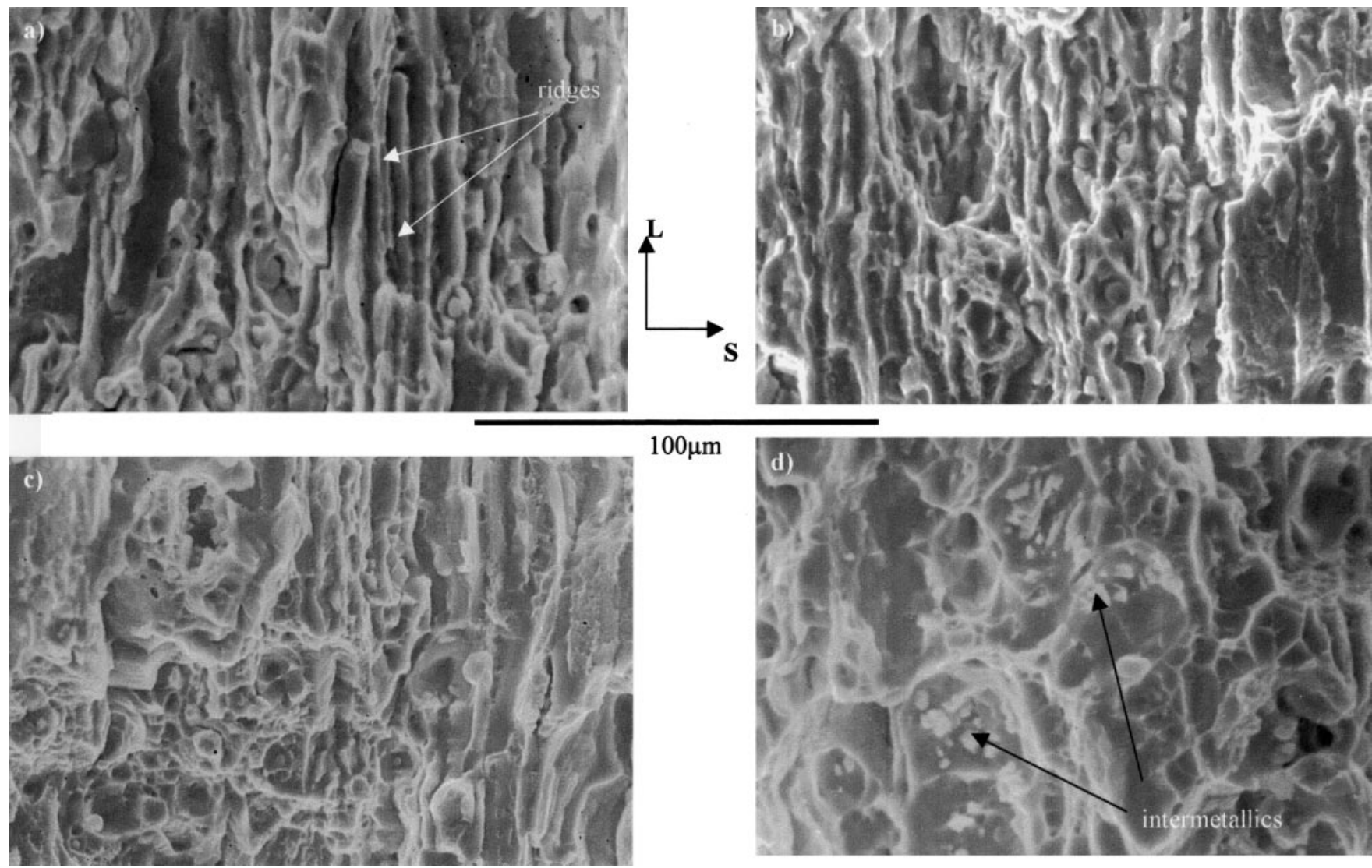

$100 \mu \mathrm{m}$

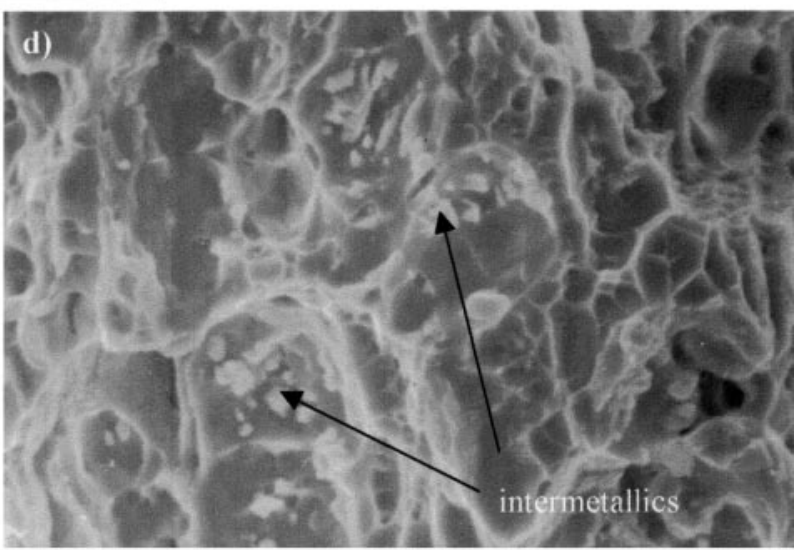

Fig. 9-SEM micrograph of fracture surface T-S plane of (a) 7449 T651, (b) 7449 T7951, (c) 7449 T7651, and (d) 7449 T7C.

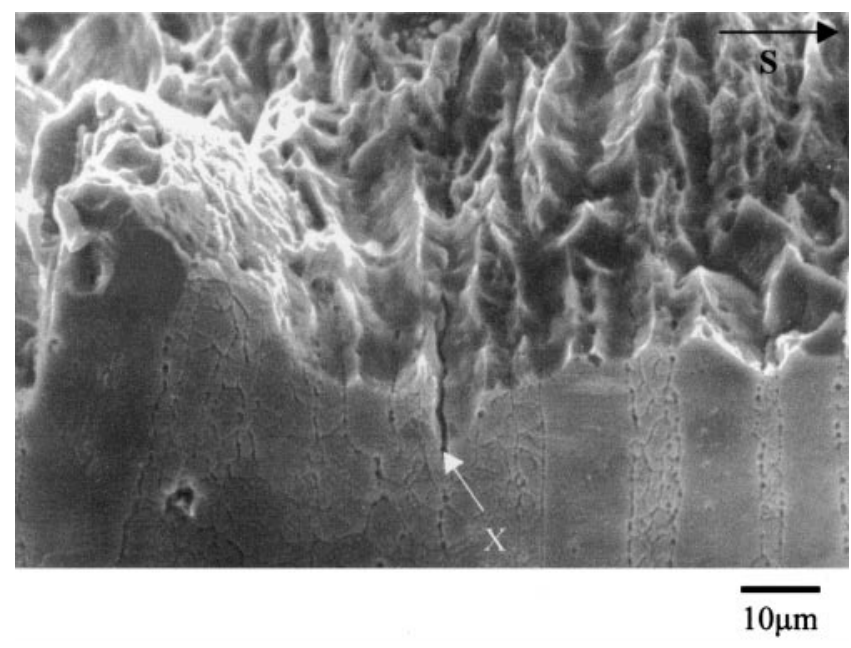

Fig. 10-SEM edge-on micrograph showing the T-S fracture plane and the polished and etched L-S plane of the 7150 T7951 alloy.

mode is influenced by the aging condition, the T7651 condition is more ductile with less ridgelike features, as compared to the T651 condition. The figures further show that in going from T651 to T7E conditions for the 7449 alloy a transition from predominantly intergranular/transgranular shear ridges in T651 conditions to principally coarse voiding in T7E condition occurs.

Edge-on observation on the L-S plane and fracture surface have clarified the nature of the linear ridges. They appear

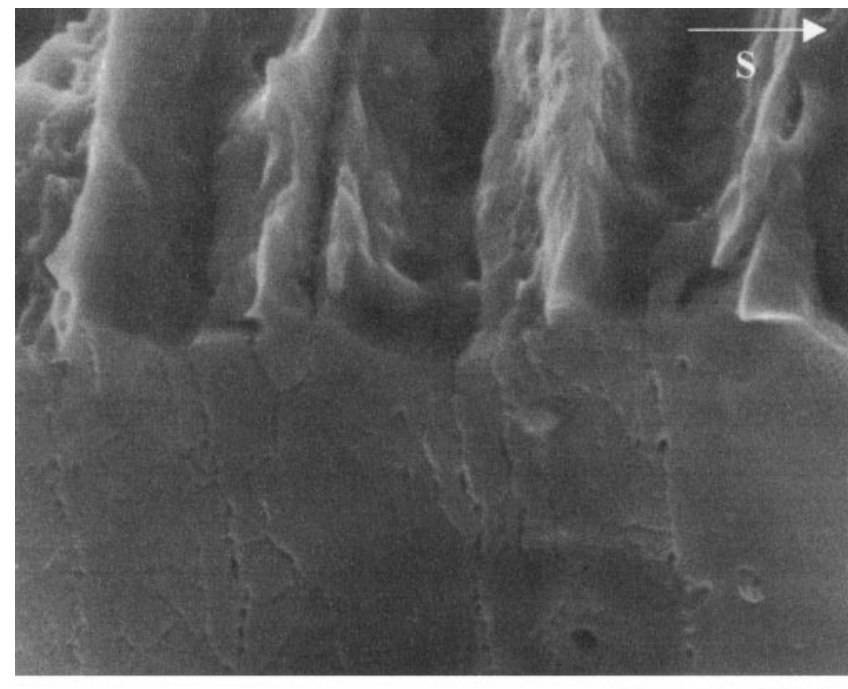

$10 \mu \mathrm{m}$

Fig. 11-SEM edge-on micrograph showing the T-S fracture plane and the polished and etched L-S plane of the 7449 T651 alloy.

to be formed from the grain boundary (Figure 10). However, the 45-deg angle of some ridges is representative of final rupture due to transgranular shear (Figure 10). An important feature of the linear ridges is that the "valley" between ridges is rarely observed to propagate down the grain boundary into the bulk of the sample. The valleys between ridges 


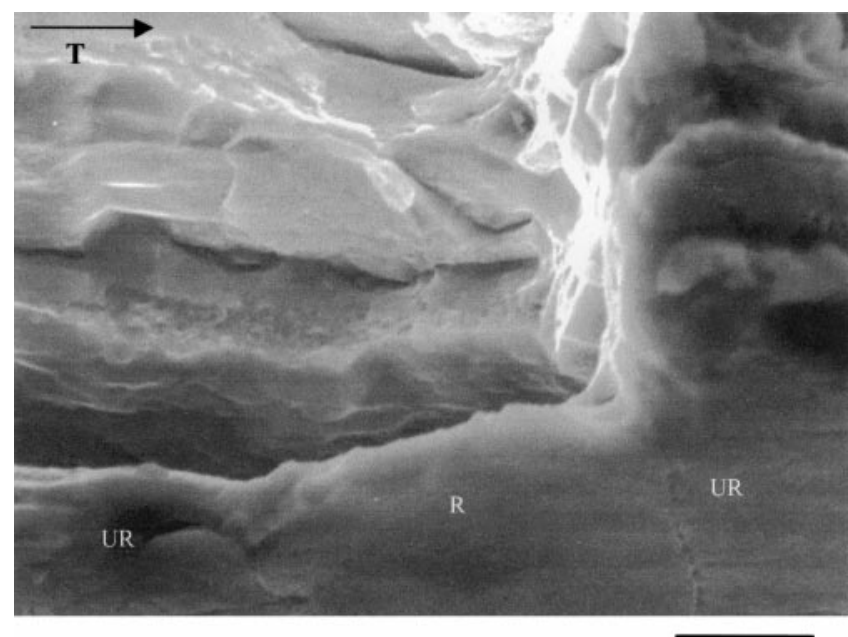

$10 \mu \mathrm{m}$

Fig. 12-SEM edge-on micrograph showing the T-S fracture plane and the polished and etched L-T plane of 7150 T7951 alloy showing recrystallized (R) and unrecrystallized grains (UR).

are generally rounded in the L-S plane. Figure 10 clearly illustrates the difference between rounded valley features and a secondary crack, which has propagated down the grain boundary, marked by " $X$ " in the figure. Such true delamination has only been observed occasionally. It is interesting to note the link between grain boundaries, which are well decorated by particles, and the ridge separations (Figure 11). From the fractographic results, it is difficult to determine whether the more decorated boundaries are grain or subgrain boundaries. However, Figures 10 and 11 show that boundaries between unrecrystallized and recrystallized grains exhibit these features suggesting that the more decorated boundaries are high-angle boundaries.

Edge-on observations of the fracture surface and the L-T plane (Figure 12) (i.e., parallel to the crack growth direction) reveal the multimechanistic nature of the fracture process. Transgranular shear through both unrecrystallized and recrystallized areas is observed, but also some influence of the grain boundary of recrystallized grains on the fracture path has been noticed for the two alloys, with some grain boundary failure occuring. Transition from linear ridges to clear grain-boundary failure was observed between recrystallized and unrecrystallized grains, but continuous linear features across transitions between recrystallized and unrecrystallized areas were also identified. While interactions between recrystallized and unrecrystallized grains were sometimes evident, little influence of substructure on crack growth was seen.

Optical microscopy observation on L-S (Figure 13) and L-T planes (Figure 14) of arrested crack specimens further illustrates the features revealed by the edge-on observations. Figure 13 shows failure at grain boundaries, where the adjacent grain has necked down to a relatively fine point (locations $\mathrm{X}$ ). However, many regions of shear decohesion are also seen (locations Y), illustrating the multimechanistic nature of the failure in this material. Multiple failure modes are highlighted in Figure 14.

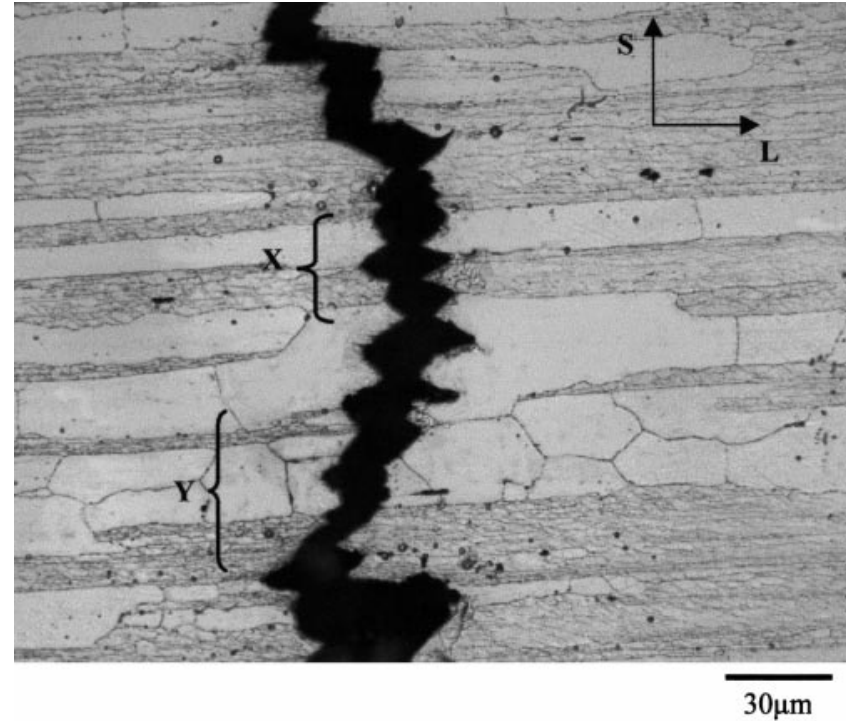

Fig. 13-Optical section (L-S) of an arrested crack in 7150 T7651: X highlights the region of grain-boundary failure and the $\mathrm{Y}$ region of shear decohesion.

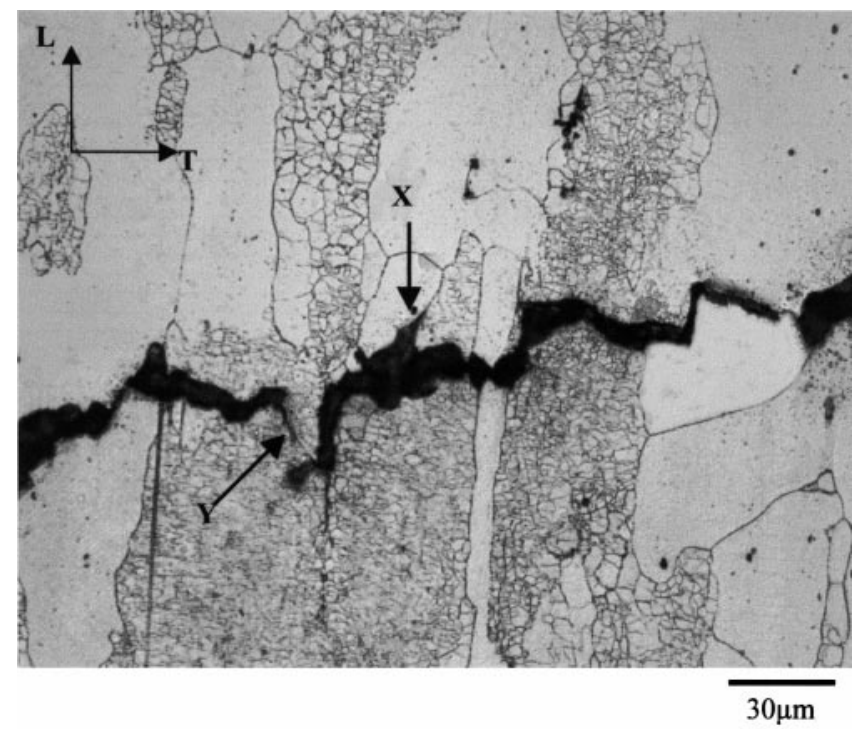

Fig. 14-Optical section (L-T) of an arrested crack in 7449 T651: $\mathrm{X}$ highlights the region of grain-boundary failure and the $\mathrm{Y}$ region of shear decohesion.

\section{DISCUSSION}

\section{A. Mechanisms of Failure}

Several mechanisms of failure were revealed by the fractographic analysis: coarse voiding at intermetallic particles and combined intergranular/transgranular shear fracture. In these failure modes, it is difficult to separate the amount of transgranular shear and grain boundary failure, as well as the interaction between coarse voiding and the other fracture processes. The SEM observation at a higher magnification on the edge of the linear ridge showed featureless areas, fine shear voiding, slip traces, and fine intergranular dimples, and this large range of features suggests complex modes 
of rupture. The complex intergranular/transgranular shearfailure mode was highlighted by the SEM edge-on observation in Figure 11. The controlling mechanism varies with aging, with combined intergranular/transgranular shear fracture dominating in the T651 condition, and coarse voiding becoming progressively more important as overaging becomes more severe.

The T651 heat treatment is associated with the higher strength of the alloy. This high strength is due to a fine dispersion of $\eta^{\prime}$ precipitates, which are obstacles to the movement of dislocations. When sheared, these precipitates create a localization of the deformation. Therefore, the ability of the alloy to accommodate strain, particularly near the crack tip, where the particles are sheared due to the presence of the plastic zone, may be limited. This localization of the deformation is strongest for the peak-aged alloys. A local critical strain sufficient to initiate transgranular shear fracture through the matrix may, therefore, be attained sooner for a given crack-tip-opening displacement in the T6 condition. Furthermore, as the strength in the matrix is high in the T6 condition, the strength differential between the matrix and the PFZ at the grain boundary, where the strength is low, creates additional strain localization that may encourage grain boundary failure. The SEM edge-on observation linking the fracture surface to the L-S plane illustrates the nature of the ridges representative of the intergranular/transgranular shear fracture, particularly indicating the influence of the grain boundaries and the grain boundary precipitates (Figures 10 and 11).

The SEM investigation has shown that the fracture path is influenced by the grain boundaries that are covered by precipitates, but when the precipitates are not present at the boundary, the boundary does not seem to influence the fracture path (Figures 10 and 11). Ludtka and Laughlin ${ }^{[23]}$ have observed a competition process between intergranular and transgranular failure that exhibits features similar to some seen here. They suggested that this process is initiated by formation of voids at the coarse precipitates at the grain boundary, with voids subsequently coalescing and extending along the grain boundary. This step is followed by the necking down of the grain interiors until fracture occurs transgranularly. It is interesting to note that while failure in our samples is clearly influenced by the decorated grain boundaries, excessive delamination of the grain structure is not evident. It would appear that for our alloy, once failure appears to occur at the boundaries, separation of the material is more dominated by triaxial opening rather than ongoing planar separation of the boundary. The form of the crack path, illustrated in Figure 10, suggests that a degree of void growth occurs at the grain boundaries rather than a separation of the boundaries. It may be suggested that the presence of a low density of grain boundary precipitates will be the cause of this mechanism. In this case, the voids formed at the grain boundary particles can grow, but their low density is an obstacle for the propagation along the grain boundary. However, precipitate sizes and PFZ features can also be expected to have an influence.

It has been reported in the literature ${ }^{[3]}$ that coarse particles fail early in the fracture process and, hence, are expected to break, even in the T6 condition. However, the low amount of coarse voiding in the T6 condition suggests that the growth of these voids would occur at a higher strain than the critical strain required for intergranular/transgranular shear fracture, i.e., the intermetallic particles do not appear to play a major role in the fracture process in the T651 condition.

During the aging treatment, the strengthening precipitates become coarser and the coarsened $\eta$ precipitates, which gradually replace $\eta^{\prime}$, can no longer be sheared, leading to more homogeneous deformation. At the same time, the strength differential between the matrix and the PFZ is reduced, giving rise to a higher deformation resistance of the grain boundary. However, there is a competition between the improved fracture resistance at the grain boundary due to the reduction of the matrix strength, and the coarsening of the grain boundary precipitates with aging. Several authors $^{[24,25]}$ have pointed out the detrimental effect of increased grain-boundary coverage by precipitates on fracture toughness as it enhances grain boundary failure. Nevertheless, enhanced grain-boundary failure on overaging has not been observed in this study. Instead, the matrix precipitation, which influences the yield strength and work-hardening parameters, $K_{A}$ or $n$, through aging, is thought to be dominant in the present alloys. As a result, in overaged conditions, coarse voiding at intermetallics becomes the main fracture mechanism. On this point, it is further noted that Morere et $a l .{ }^{[16]}$ have suggested that intermetallics promote transgranular fracture in an indirect way, namely through promoting recrystallization by acting as preferential nucleation sites for recrystallization. ${ }^{[16,26]}$ In the absence of subgrains to homogenize the deformation, the strain is localized at the hard intermetallics within the softer recrystallized grain, promoting the formation of voids.

\section{B. Toughness Behavior}

The changes in toughness of the 7150 and 7449 alloy resulting from aging and the differences between alloys are determined by microstructural features and their associated influences on the mechanisms of failure. In Figure 7, the 7150 and 7449 alloys fall in the same region of the strengthtoughness line in the T651, T7951, and T7651 conditions, illustrating that the difference in properties between the two alloys is related mainly to the higher amount of Zn-containing strengthening precipitates in the 7449 alloy. This figure also illustrates the influence of alloy purity on the toughness-strength relationship: the 7475 alloy, which is known to have a higher purity than the 7075 alloy, ${ }^{[2]}$ has a higher toughness for the same level of strength than the 7075 alloy.

The S-phase intermetallics are expected to promote failure through coarse voiding. ${ }^{[22,27]} \mathrm{S}$ phase can be-suppressed by a combination of high solution-treatment temperature and a limited $\mathrm{Cu}$ and $\mathrm{Mg}$ content such that all $\mathrm{S}$ phase can be dissolved at the solution treatment temperature. ${ }^{[27,28]}$ In the 7449 alloy, suppression of S phase was achieved by decreasing the copper content relative to that in the 7150 alloy (the present 7449 alloy has a $\mathrm{Cu}$ content that is $0.3 \mathrm{wt}$ pct lower than that of the 7150 alloy). Notwithstanding the difference in $\mathrm{S}$ phase content, the 7449 and 7150 alloys have a similar strength-toughness relation for T6, T79, and T76 conditions (Figure 7). It is thought that the higher content of $\mathrm{S}$ phase in the 7150 alloy than in 7449 alloy is not detrimental to the 7150 alloy, as coarse voiding at intermetallics contributes 


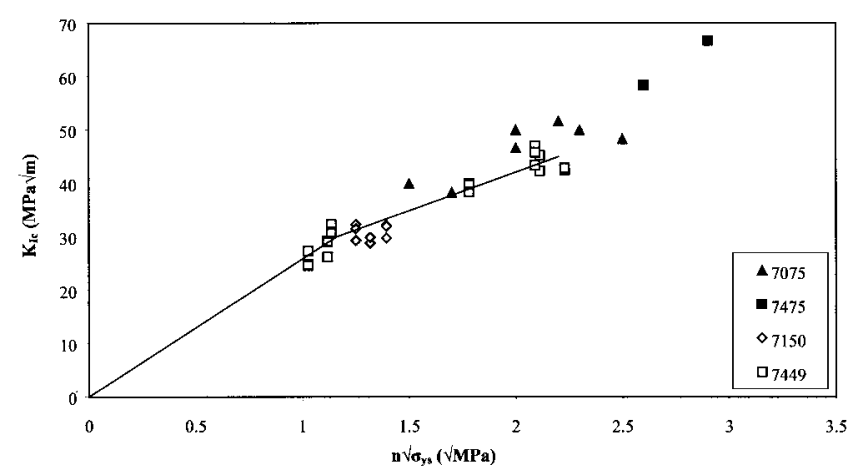

Fig. 15-Relationship between $K_{I c}$ and $n \sqrt{\sigma_{y s}}$.

only a limited extent to the fracture process in the peakaged conditions. Going to more overaged conditions, coarse voiding at intermetallics becomes progressively more important, and thus, the $\mathrm{S}$ phase in 7150 would be expected to limit the recovery of toughness with decreasing strength of the 7150 alloy.

In the T651 condition, the 7150 alloy appears to exhibit a toughness that is somewhat higher than for the 7449 alloy at equivalent strength. If the intensity of shear banding/ instability is linked to the total capacity for work softening within a slip band, then, the higher $\mathrm{Zn}$ content and, therefore, higher $\eta^{\prime}$ precipitate density of the 7449 alloy may be more detrimental for this alloy than for the 7150 alloy. The dependence of the strength on $\eta^{\prime}$ precipitation is well known and has been highlighted in the literature. ${ }^{[2]}$ It is suggested that in 7150, in slightly overaged T7951 and T7651 conditions, the degree of shear instability is still lower than for 7449 , balancing the detrimental effect of the $\mathrm{S}$ phase.

\section{Toughness Modeling}

As compared to the 7xxx alloys used to assess the Garrett, and Knott-type models in the past, ${ }^{[4,5]}$ the 7150 and 7449 alloys possess a lower toughness, higher strength, and lower work-hardening coefficient, $n$. Hence, it is valuable to compare our present data with predictions by the Garrett and Knott model. The Garrett and Knott model predicts that for a sample failing through the same mechanism, $K_{I c}$ is proportional to $n \sqrt{\sigma_{y}}$. However, Figure 15 shows that is not the case for the 7449 alloy over the range of aging treatments studied and, in fact, the data on peak-aged and slightly overaged conditions (until T7651) show a steeper slope than the more overaged conditions. Two explanations for this deviation from the Garrett and Knott model are suggested. A first explanation for this is the modification of fracture mode with aging of this alloy. The Garrett and Knott model, which essentially is a single mechanism model, would generally be expected to fail under these circumstances. For the peak-aged and slightly overaged 7150 and 7449 alloys, the high strength of these alloys promote the multimechanistic aspects of the fracture process with a competition between coarse voiding and transgranular/intergranular failure. In more overaged tempers, the fracture mode is dominated by a single mechanism: coarse voiding initiated at coarse intermetallics. One may consider that including the critical strain as a variable parameter in the Garrett and Knott model may improve the accuracy. This was tested through obtaining

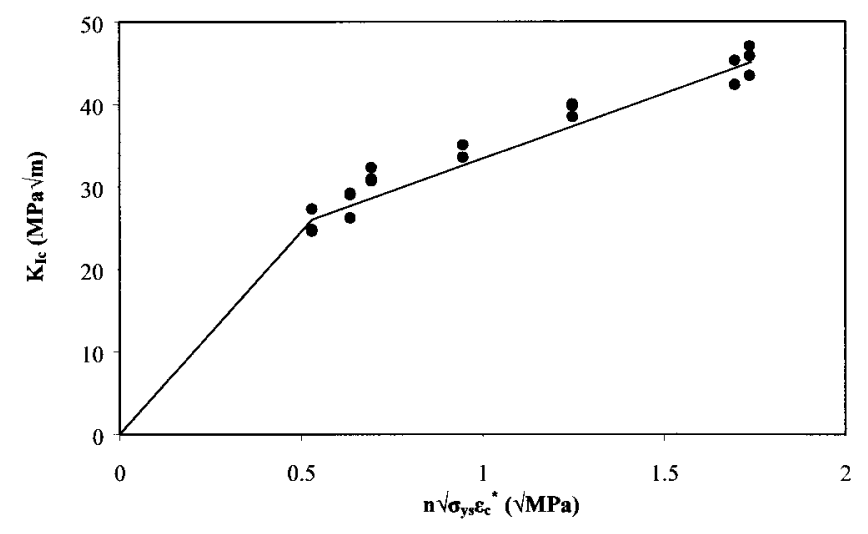

Fig. 16-Relationship between $K_{I c}$ and $n \sqrt{\sigma_{y s} \varepsilon_{c}^{*}}$ for the 7449 alloy.

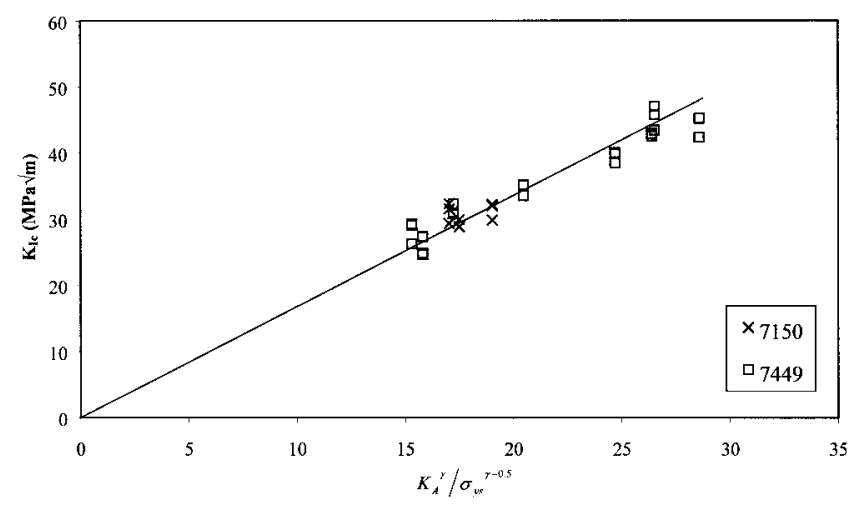

Fig. 17-Graph of $K_{I c} v s K_{A}^{\gamma} / \sigma_{y s}^{\gamma-0.5}$.

the critical strain from reduction in area data, and the result is plotted in Figure 16. This figure shows that variable critical strain deduced by simple reduction of area in smooth tensile specimens does not enhance the linearity of the predicted relationship, i.e., the coarse voiding dominated T7A to T7E conditions are still below the linear prediction. Here, it should be noted that the critical strain values obtained in this simplified manner may not be an accurate estimation of the triaxial stress state in plane-strain fracture-toughness testing.

The relation between tensile properties and toughness has also been studied with the new model (Eq. [6]) presented in Section III, which relies on the Ashby work-hardening factor, $K_{A}$. The $K_{A}$ value is influenced by the grain structure of the alloy and the nonshearable particles present in the matrix. As $\eta$ particles are the only nonshearable particles that are susceptible to variation in density and size with aging, the variation of $K_{A}$ is related to changes in the $\eta$ precipitate sizes and density through aging. Specifically, in overaged conditions, a transition to Orowan looping is expected to increase the work-hardening factor in the 7449 alloy.

The new model predicts $K_{I c}$ to be proportional to $K_{A}^{\gamma} / \sigma_{y s}^{\gamma-0.5}$ and Figure 17 shows that for the present data on 7449 this prediction holds up well. In fact, this predicted proportional relation holds up better for the new model, as compared to the equivalent proportional relation prediction by the Garrett and Knott model (Figure 15), i.e., in Figure 17, a straight line through the origin can fit the data while this is not possible in Figure 15 (or Figure 16). Similar to 
Garrett and Knott's model, this new model is still only valid for a single mechanism of failure, but this does not seem to adversely influence its accuracy. In the first instance, it may be suggested that the improved accuracy of this new model is due to the elimination of $n$ from the model; however, this would require further analysis.

This enhanced "accuracy" of the model is clearly an advantage. The model furthermore describes work hardening using a parameter $\left(K_{A}\right)$ that can be related directly to the microstructure. It was shown in Section IV and Table V that this description of work hardening (the Ashby model) is more accurate than the conventional exponential (Ramsberg-Osgood) work-hardening equation. The new model also shows explicitly that toughness increases with decreasing strength. It is also valuable to note that the driving parameters of the fracture model are to a large extent uncoupled, i.e., the parameter describing macroscopic work hardening, $K_{A}$, does not depend directly on $\sigma_{y s}$. (Note though that some microstructural features, such as nonshearable particles, can effect both the strength and $K_{A}$, thus causing some interrelation to remain.)

From the preceding, it may be taken that the Garrett and Knott model for the relation between yield strength, work hardening, and toughness has clear limitations. The improved results obtained by the new model, which includes the Ashby model for strain hardening, would suggest that the use of $n$ as a parameter for strain hardening is inaccurate and that the Ashby model for strain hardening is a better approximation. The applicability of both models is limited by the simplification of considering a single failure mechanism. A truly comprehensive model of fracture toughness has to consider all fracture modes (coarse voiding at large intermetallics, transgranular shear fracture, and intergranular fracture), the parameters that influence these fracture modes (yield strength, grain boundary precipitation, PFZ, coarse intermetallics, and grain structure) as well as the anisotropy of some of these parameters (distribution of intermetallics and dispersoids, and orientation of the grain structure). All these processes are linked, and interactions between them may be expected. Several attempts to model toughness with a multimechanistic approach have been attempted. Hornbogen and $\mathrm{Graf}^{[29]}$ have proposed a linear summation of specific intergranular and transgranular fracture toughness weighted by their respective area fraction on the fracture surface. Gokhale et al., ${ }^{[30]}$ considering fracture toughness as an energy parameter, have used a squared summation of $K_{I c}$ for specific fracture mechanisms with a weight function based on the area fraction of the respective mechanisms.

\section{CONCLUSIONS}

Differential scanning calorimetry, in combination with SEM and TEM, showed that the principal differences in the microstructure between the 7449 and 7150 alloys are the amount of $\eta^{\prime}$ phase, which is higher for the 7449 alloy, and the presence of some coarse $\mathrm{S}$ phase in the 7150 alloy, which does not appear in the 7449 alloy. In T6 conditions, the higher amount of $\eta^{\prime}$ phase gives the 7449 alloy a yield strength that is about $20 \mathrm{MPa}$ higher than the 7150 alloy.

The SEM on fracture surfaces and polished sections through cracks and interrupted cracks showed that fracture in 7449 and 7150 is multimechanistic: grain boundary failure, transgranular shear, and coarse voiding at large intermetallics occur. The amount of coarse intermetallics is important, as coarse voiding at large intermetallics becomes more predominant with overaging. On overaging, the toughness recovers, and the yield strength vs toughness plot is approximately linear. The work hardening in the samples can be described reasonably well using the Ashby work-hardening model for hard particles in a soft matrix.

The complex interaction between the failure mechanisms and the variation of many parameters with the aging treatment make the attempts to model fracture toughness difficult. The Garrett and Knott model, which predicts a linear relation between $K_{I c}$ and $n \sqrt{\sigma_{y s}}$, fails to predict the data on these high-strength alloys satisfactorily. A new modeling approach, incorporating the Ashby model for work hardening is derived. The model correctly predicts an increasing toughness with decreasing strength and accurately describes the dependence of toughness on yield strength and work hardening for a given alloy.

\section{ACKNOWLEDGMENTS}

The provision of plate material by Pechiney CRV is gratefully acknowledged.

\section{REFERENCES}

1. T.J. Warner, R.A. Shahani, P. Lassince, and G.M. Raynaud: 3rd ASM Conf. on Synthesis, Processing and Modelling of Advanced Materials, Paris, France, June 1997.

2. I.J. Polmear: Light Alloys: Metallurgy of the Light Metals, 3rd ed., Edward Arnold, London, 1995.

3. G.T. Hahn and A.R. Rosenfield: Metall. Trans. A, 1975, vol. 6A, pp. 653-68.

4. G.G. Garrett and J.F. Knott: Metall. Trans. A, 1978, vol. 9A, pp. 1187-1201.

5. G.T. Hahn and A.R. Rosenfield: Applications Related Phenomena in Titanium Alloys, ASTM STP 432, ASTM, Philadelphia, PA, 1968, pp. 5-32.

6. C.Q. Chen and J.F. Knott: Met. Sci., 1981, vol. 15, pp. 357-65.

7. M.J. Starink and P.J. Gregson: Mater. Sci. Eng. A, 1996, vol. 211, pp. 54-65.

8. M.J. Haynes and R.P. Gangloff: Metall. Mater. Trans. A, 1997, vol. 28A, pp. 1815-29.

9. N. Eswara Prasad, S.V. Kamat, K.S. Prasad, and G. Malakondaiah: Eng. Fract. Mech., 1993, vol. 46, pp. 209-23.

10. G. LeRoy, J.D. Embury, G. Edward, and M.F. Ashby: Acta Metall., 1981, vol. 29, pp. 1509-22.

11. M.F. Ashby: in Strengthening Methods in Crystals, A. Kelly and R.B. Nicholson, eds., Elsevier, Amsterdam, The Netherlands, 1971, p. 137.

12. M.F. Ashby: Phil. Mag., 1966, vol. 14, pp. 1157-78.

13. P. Gomiero, Y. Brechet, F. Louchet, A. Tourabi, and B. Wack: Acta Metall. Mater., 1992, vol. 40, pp. 857-61.

14. M.J. Starink, P. Wang, I. Sinclair, and P.J. Gregson: Acta Mater, 1999 , vol. 47, pp. 3855-68.

15. J.W. Hutchinson: Proc. R. Soc. London A, 1970, vol. 319, pp. 247-72.

16. B. Morere, J.-C. Ehrstrom, P.J. Gregson, and I. Sinclair: Metall. Mater. Trans. A., 2000, vol. 31A, pp. 2503-15.

17. G. Lapasset and C. Renon: Recherche Aérospatiale, 1982, vol. 5, pp. 313-26.

18. X. Li and M.J. Starink: Mater. Sci. Forum, 2000, vol. 331, pp. 1071-76.

19. R. DeIasi and P.N. Adler: Metall. Trans. A, 1977, vol. 8A, pp. 1177-83.

20. A. Deschamps, F. Livet, and Y. Bréchet: Acta Mater, 1999, vol. 47, pp. 281-92.

21. J.M. Papazian: Metall. Trans. A, 1982, vol. 13A, pp. 761-69.

22. A.J. Morris, R.F. Robey, P.D. Couch, and E. De Ios Rios: Mater. Sci. Forum, 1997, vol. 242, pp. 181-86.

23. G.M. Ludtka and D.E. Laughlin: Metall. Trans. A, 1982, vol. 13A, pp. 411-25. 
24. A.K. Vasudevan and R.D. Doherty: Acta Metall., 1987, vol. 35, pp. 1193-1219.

25. I. Kirman: Metall. Trans., 1971, vol. 2, pp. 1761-70.

26. J. Yeh and K. Liu: Scripta Metall., 1986, vol. 20, pp. 329-34.

27. M.R. Jarrett and J.S. Compton: Proc. Conf. on Extrusion of Hard
Alloys, Associazione Italiana di Metallurgia, Milan, Italy, 1991.

28. X. Li and M.J. Starink: Mater. Sci. Technol., 2001, vol. 17, pp. 1324-28.

29. E. Hornbogen and M. Graf: Acta Metall., 1977, vol. 25, pp. 877-81.

30. A.M. Gokhale, N.U. Deshpande, D.K. Denzer, and J. Liu: Metall. Mater. Trans. A, 1998, vol. 29A, pp. 1203-10. 